\title{
Mobile Technology in Higher Education - Give it a Go: A Perspective from Bioscience
}

\author{
Daniel James Peart \\ Northumbria University
}

\begin{abstract}
Barriers, as perceived by teachers, towards the acceptance of new and emerging technologies in teaching and learning are well reported in the literature. This article offers a reflection upon a project that observed student use of mobile technologies to support their learning. It was apparent that the main use of the technology was for self-directed learning and not for subject-specific studies or use within the classroom. It is suggested that teaching staff need not feel pressured by students to be technology experts and are encouraged to work in partnership with their students to evaluate the potential of such technologies for supporting learning.
\end{abstract}

Key words: Self-directed, informal, iPads, mobile education

\section{Introduction}

The use of mobile technologies to support teaching and learning in Higher Education is becoming much more popular and even necessary as a generation of school children that will ultimately become our students is already familiar with it (Henderson and Yeow, 2012, Looi et al, 2011, Looi et al, 2016, Pegrum et al, 2013). During the 2013/14 academic year, we trialled the implementation of such technology with a small cohort of sixteen level 5 Foundation degree (FdSc) Bioscience students, studying in a University Centre based within a Further Education College. The tuition fees for these students were increased to cover the costs associated with the purchase of an iPad mini and iTunes vouchers, which became the personal property of the student. At the end of the academic year, students were unanimous in favour of these devices as support for their teaching and learning, identifying, amongst other things, how they facilitated research, communication and laboratory record keeping. Moreover, the staff team highlighted the fact that they had witnessed an increase in student subject reading (through e-journals and/or mobile applications - Apps), and also provided examples of how the technology offered alternative methods for teaching the module content. The case study was presented in a staff-student collaborative manner at two regional (Peart et al, 2014c, Peart et al, 2014d) and one national conference (Peart et al, 2014a), and resulted in the publication of an academic paper (Peart et al, 2014b). The pilot work was generally well received by conference audiences, though many of the questions put to us were focused on the logistical barriers to using such technology and staff anxieties about their knowledge of the technologies, as opposed to the potential benefits. These exchanges were also evident during internal staff development presentations, where such comments as 'I wouldn't know where to start', 'I don't get on with computers' or 'I can't see the relevance for my subject area' were frequent. 


\section{Staff anxiety towards technology}

A review of the literature would suggest that these responses are not uncommon. Gong et al (2004) and Blackwell et al (2014) both proposed that 'computer self-efficacy' was the cornerstone of teachers' perception of the usefulness of technology and their subsequent intention to use it in practice. Furthermore, Teo et al (2008) suggested that confidence with technology needs to be embedded during teacher training, if its use in the classroom is to be promoted, and Louw (2015) has gone so far as to propose a specific workshop to help staff. The staff anxieties that we encountered, alongside the apparently commonplace concerns about personal proficiency as reported in the literature, led us as teaching staff to ask ourselves the important question: 'Did we actually do anything, or was it the students?'

\section{Do the students need staff input?}

On reflection, it was difficult for staff members to identify any specific input by them into the pilot project and it appeared that the students were the main driving force. A further question arose from this: 'Do the students actually need any input from us to embed the technology into their learning?' To go some way towards answering this question, the six students who had progressed on to BSc level 6 top-up year in 2014/15 at the validating university were invited to complete an online questionnaire (five responded). Our purpose in doing this was to find out whether they still used the devices, even if their new lecturers were not promoting their use as we had done, as those staff had no knowledge of the pilot study. A detailed review of the responses is beyond the scope of this opinion piece, though an overview of questions and individual answers is presented in Table 1 for readers' perusal.

\section{Implications for practice}

It would appear that the students continued to use the mobile device at their new institution in the same way, despite the staff there not being a part of our pilot project. This would suggest that the students had no expectation that the staff would use the technology in their teaching, and that they saw the devices as personal tools. Similarly, Rung et al (2014) have observed that students use mobile devices to support their learning despite their not being formally included in the curriculum. This may be because students reported that their main use of the technology was for such self-directed purposes as on-hand research and reviewing work. This was in accord with our observations during the pilot year (Peart et al, 2014b) and also with those of other authors who have reported that mobile devices are used primarily by students for self-regulated learning (Sevillano-Garcia and Vazquez-Cano, 2015) and to enhance learning outside the classroom (Foti, 2014). Interestingly, none of the uses mentioned by the students were subject-specific, which again implies that teaching staff do not necessarily need to feel pressured to 'find' uses for mobile devices in their subject areas. Finally, the comment that the devices are a 'useful tool but not necessarily essential' may go some way to assure the teacher/lecturer that the student sees her/his main role as that of a subject specialist and not an expert in technology. 
Table 1: Survey Questions and Responses

\begin{tabular}{ll}
\hline Question & Responses \\
\hline Looking back at last year was & 1.The iPad was very useful during the academic year \& for personal use thereafter. \\
the iPad a useful addition to & 2.Yes, fantastic for on hand research. Relevant, easy to use apps. \\
your studies? & 3.Yes, it was. It helped that we were able to download the learning materials prior to the \\
lecture (providing it was put onto the site in time) and open it up in the Explain \\
Everything App. That way notes could be made directly on the lectures slides and it \\
could also be recorded. \\
4. Yes, used a lot to record lectures, for making notes, researching and enabled to \\
download reading material. \\
5.Yes, very useful for final year studies.
\end{tabular}

Did having the iPad help with the step up to level 6 in any way?

Has your overall use of the iPad changed since moving to your new institution? What specifically do you use the iPad for?

Do you feel that your learning experience at the University is improved with the use of the iPad? Would you manage as well without the iPad?

On an average day at University how often would you say you used your iPad?

As a final thought, would you recommend that a student used an iPad (or similar tablet device) to support their studies?
1. Easy to refresh on previous studies and excellent for research and revision.

2. It made the transition easier.

3. Yes not only has it been useful in order to record lectures but as a lot of the library books are available online, it is a useful tool for reading and downloading journal articles.

4.Yes, was easier to download the lectures at level 6 and be more organised without the cost of always printing off lectures. It also meant I could record the lectures once again to go over and for revision. Also very useful to manage time on the train, able to download reading again.

5. Yes.

1.I use the iPad daily at University to access Blackboard so I know of any lesson alterations, available lesson plans.

2.Lectures and downloading journal articles. Also quick research in lectures.

3. No, I still use the iPad \& even more now. I commute to University \& can easily access information while travelling.

4.Used much more for research and less note taking. Particularly useful in lessons with unfamiliar terminology to quickly revise.

5. Very similar as I used it a lot before and continue to do so now, also take a lot more notes and form more ideas on it. Use it in other ways too and generally in other jobs, it is very easy to check the timetable which is online and refer back to other lecture materials and module books which are on the blackboard site

1. Additional support is required for the transition, not just self directed iPad study.

2.I feel I have integrated the iPad in to my learning in general and feel it is a beneficial tool at all levels.

3. Maybe, but it is useful addition as it minimises the amount of books that you have to transport.

4. Very subjective opinion. Without the iPad I would have to carry big books to facilitate \& incorporate extra reading.

5. Yes it is improved, I think without it I would not be as organised and able to access all work as easily. So would probably be less productive or have to carry a lot more equipment/books etc. Also it has helped to be able to record the lectures. It is also possible with a Dictaphone, but with the Explain Everything App I can also link to lecture slides, so even if I don't understand the lecturer at that point it is easy to review.

1.I use the iPad $100 \%$ of the time \& I'm happy with it.

2. In most of the lectures, occasionally in the library or when we have a break.

3. Not very often.

4. Often throughout the day and evening.

5.Very regularly, on the train there and back, and whilst at university during lectures the majority of the time as well as between.

1.Depending on research and revision strategy. Not overly helpful for day to day lectures, but for self directed work. Had I not have received one through the pilot scheme; I would have purchased one personally.

2.I would recommend the use of iPad. It is easy to get the course work \& be organised. 3. Yes

4. Yes definitely, I think if they are already relatively computer literate it is very easy and you can utilise it to integrate well into your life and organise. Most lecturers encourage the use of technology and so accessing it easily helps.

5. Yes I would recommend an iPad or something similar. It may benefit students to be issued with a laptop so that they have access to a computer at all times. 


\section{Summary}

In summary, it is advocated that teaching staff do not need to be anxious about the emerging presence of mobile technologies in education. This article and other past research has presented evidence that students use such technology primarily for non-subject-specific selfdirected learning; teaching staff do not therefore need to feel pressured by the students to embed the technology into their own teaching and learning. Moreover, staff interested in starting out with such technology may not necessarily need to make any deliberate steps, as there is the potential for the student to find the 'fit'.

These are the opinions of one author, and the information presented should be interpreted as such. It is also acknowledged that the opinions presented in this article have been formulated on the basis of evidence from a relatively small and specific cohort of students. However, it is hoped that the uncomplicated approach used in this case study may encourage teaching staff to work with their students and take the time to find a natural fit for the technology in their practice.

\section{Acknowledgments}

The opinions presented in this article have been shaped in some part by discussions with colleagues and students. I should like to acknowledge the following: Matthew Shaw, David Cross, Steven Johnstone, Dr Chris Rowley, Pumlani Bangani, Jessica Brown, and Orrin Fairhead.

\section{Reference list}

Blackwell, C. K., Lauricella, A. R. and Wartella, E. (2014) 'Factors influencing digital technology use in early childhood education.' Computers \& Education, 77, 82-90.

Foti, M. K. (2014) 'Mobile learning: How students use mobile devices to support learning.' Journal of Literacy and Technology, 15(3), 58-78.

Gong, M., Xu, Y. and Yu, Y. (2004) 'An enhanced technology acceptance model for webbased learning.' Journal of Information Systems Education, 15(4), 365-374.

Henderson, S. and Yeow, J. (2012) 'Ipad in education: A case study of ipad adoption and use in a primary school.' 45th Hawaii International Conference on System Science (HICSS), 78-87.

Looi, C.-K., Lim, K. F., Pang, J., Koh, A. L. H., Seow, P., Sun, D., Boticki, I., Norris, C. and Soloway, E. (2016) 'Bridging formal and informal learning with the use of mobile technology.' In: Chai, S. C., Lim, P. C. and Tan, M. C. (eds.) Future learning in primary schools: $A$ singapore perspective. Singapore: Springer.

Looi, C. K., Zhang, B., Chen, W., Seow, P., Chia, G., Norris, C. and Soloway, E. (2011) '1:1 mobile inquiry learning experience for primary science students: A study of learning effectiveness.' Journal of Computer Assisted Learning, 27(3), 269-287. 
Louw, A. (2015) 'Developing a lecturer workshop for using tablets in the classroom.' International Journal of Teaching and Learning in Higher Education, 27(3), 294-309.

Peart, D. J., Johnstone, S., Brown, J. and Bangani, P. (2014a) 'Supporting teaching and learning in biosciences with mobile technology: Staff and student perspectives.' University Centre, Yeovil: Convergence Academic Research Conference.

Peart, D. J., Johnstone, S., Brown, J. and Bangani, P. (2014b) 'Supporting teaching and learning in biosciences with mobile technology: Staff and student perspectives.' The Journal of Research in Higher and Further Education, 2(1), 5-10.

Peart, D. J., Johnstone, S., Brown, J. and Bangani, P. (2014c) 'The use of mobile technologies in biosciences: A case study.' Manchester University: Jisc E-Learning in HE Conference.

Peart, D. J., Johnstone, S., Brown, J. and Bangani, P. (2014d) 'The use of mobile technologies in biosciences: A case study.' Leeds Beckett University: Jisc Digital Festival.

Pegrum, M., Oakley, G. and Faulkner, R. (2013) 'Schools going mobile: A study of the adoption of mobile handheld technologies in western Australian independent schools.' Australasian Journal of Educational Technology, 29(1), 66-81.

Rung, A., Warnke, F. and Mattheos, N. (2014) 'Investigating the use of smartphones for learning purposes by Australian dental students.' JMIR mHealth and uHealth, 2(2), 20.

Sevillano-Garcia, M. L. and Vazquez-Cano, E. (2015) 'The impact of digital mobile devices in higher education.' Educational Technology \& Society, 18(1).

Teo, T., Lee, C. B. and Chai, C. S. (2008) 'Understanding pre-service teachers' computer attitudes: Applying and extending the technology acceptance model.' Journal of Computer Assisted Learning, 24(2), 128-143. 